\title{
Designing with type, part 2
}

\author{
By Susan Jurist
}

\section{Just because you shouldn't, doesn't mean you can't}

$\mathbf{T}$ he first part of this article, which appeared in the March issue, discussed traditional standards for using fonts in both print and electronic situations-standards unknown to, or ignored by, a large proportion of our profession. The rules in Part 1 are most applicable when preparing reports, writing articles for publication, or creating Web pages for official purposes. This second part expands your use of font choices, both for traditional publications (if you are brave) and for less formal situations like newsletters, flyers, and handouts.

American Typewriter(Adobe)
$\begin{gathered}\text { Benguiat Gothic (Adobe) Amnesia (TypoArt) } \\ \text { Bodegd Sans/Sans Oldstyle/Serit/Serif Oldstyle (FontBureau/lpla) }\end{gathered}$

URW Bodoni (Maeromedin) $\mathbb{V}$ Courier (Apple)

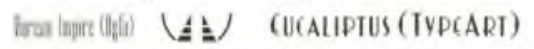
Eurostile Extended Two (Adobe)

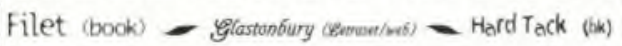
Q Helvetica (Adobe) VIntention ([T-26]) Tsadera (Adobc) \& Lower West Side (web) Mason/masen Altermate (Emigre)

Wonkey Caught Stealing (Garagefonts) 娄 Officina Sans/Serif (Adobe) Dos Optima (Adobe)

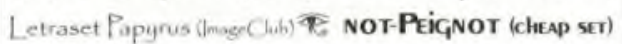

$$
\text { zuatins/Solid (Adeba) }
$$

Russell Square (Adabe) $\mathbf{x}$ Serpentine (Adobe)

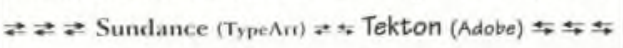
$\checkmark$ Tema Cantante/ Sans ([T-26]) $\vee$ Times (Apple) $Q$ vintage Thpownter(reb) 起 (Whassis) (Adebe)

Figure 1. A selection of fonts including picture fonts from Adobe, Agfa, Font Haus, and others.
Figure 1 is an illustration of all the fonts mentioned in the article that I oun. If I own a font, its name will be in italics in the text and illustrated in Figure 1, followed by the source where I obtained the font-not the sole source in most cases. If I don't own a font, I will indicate a source for that font following its name. For ease of finding, and because some fonts are referred to more than once, they are in alphabetical order. If you are not familiar with type catalogs, you should know that when the type house is part of the font name, it is ignored in the alphabetizations. For example, Letraset Papymus will appear with the "Ps" not the "Ls." Picture fonts mentioned in the article are in Figure 5.

\section{Name dropping continued}

The fonts clescribed in Part 1, the ubiquitous Times and Helvetica and their alternatives, all are safe, traditional choices. There are times, however, when you want a different lookespecially when trying to attract the attention of an undergraduate population raised on "zines" and Wired magazine. If familiarity is a precursor to readability, we need to examine the styles these students are reading. While fonts are as trendy as fashion and can become cliched quicker than faculty returning a book for reserve the day before midterms, these trendy fonts are fun to use and are not inappropriate for library use. Though I describe some specific fonts I use, the stylistic reasons can be applied to any number of other well-designed fonts.

A good example is the versatile Bodega which is used by Mcllonald's, the U.S. Post Office, two national pizza chains, many record and book publishers, and even the brand of cat food my cats prefer (California Chicken Supreme anyone?). Bodega comes in both serif and sans-serif as well as serif old-style and sansserif old-style. I love Bodega because its letter 
forms are elegant and attractive (with a full but impertinent bouquet). Bodega also has compressed letter forms which are invaluable for putting a lot of information in a horizontally small space, without losing readability.

Figure 2 is an example of the mood a font gives to a simple phrase. The first two, the dreaded Times and Helvetica, say "we are a traditional library - come to our orientation and be bored to tears." The two Bodega examples are lighter and imply that the orientation is less formal and may be an OK thing to do (the serif old style, just a bit more formal). Even though all the fonts in this figure are the same type size (vertical height), only Bodega can fit the information on one line.

Tekton is another font that has been used in every conceivable location (and also appears in McDonald's print and TV ads). Its handwritten style is perfect for an informal look but can be dressed up with an appropriate layout. Because of its architectural connotations, Tekton is the font we use for our Art \& Architecture Library newsletter, setting both the type and the headings in varying weights and sizes for differentiation. Its simple shapes make it perfect for small, legible text, even with the poorest reproductions. Figure 3 is an excerpt from the latest newsletter.

Highly stylized fonts from font houses like Emigre give an extra sense of place to your work. Emigre's Mason and Exocet are featured heavily on the covers of mystery and science fiction books and CD covers. They are familiar to those audiences but are still readable for the uninitiated. The use of Mason in figure 2 says, "come to the mysterious library where you will be introduced to strange and wonderful things."

A few other fonts you will also see everywhere are Bertbold City, Font Bureau's SamSans and Armada, Letraset Papyrus, Russel Square, Officina Sans, and Officina Serif. What these fonts have in common is that they are all slightly quirky but can be used in (somewhat) traditional settings. I've used Officina for library promotional flyers as well as a class syllabus (fig-

\begin{tabular}{|c|c|}
\hline & $\begin{array}{l}\text { Library Orientation } \\
\text { Every Monday, 10-12 }\end{array}$ \\
\hline & $\begin{array}{l}\text { Library Orientation } \\
\text { Every Monday 10-12 }\end{array}$ \\
\hline Libr & Orientation - Every Monday 10-12 \\
\hline Libra & y Orientation - Every fllonday 10-12 \\
\hline LiB & $\begin{array}{l}\text { ARY ORIEMfAfIOI } \\
\text { EVERY MOMDAY I O-I } 2\end{array}$ \\
\hline & $\begin{array}{r}\text { Library Orientation } \\
\text { Mondays } 10-12\end{array}$ \\
\hline
\end{tabular}

Figure 2. A phrase by any other font ...

ure 4) - the best fonts are adaptable to a variety of situations-and it's the font used to indicate font names in figure 2 .

\section{Grunge is more than a state of mind}

Grunge is also a font. As grunge music was a reaction to slickly produced rock, grunge fonts (also called "dirty" or even "ugly") are type designers' adverse reactions to the perfectly slick fonts computers are capable of generating. Analog fonts have variances inherent in mechanical reproduction, so type designers reintroduced the "chirt" as it were. If you really want to go over the edge, invest in a couple of grunge fonts. While some traditional type designers are breathlessly waiting for the trend to end, these fonts give a very "now" look to your publications. Some, like Amnesia, are just a bit irregular in form. Next are funkier fonts like Hard Tack, going all the way to the completely unreadable.

Some of the classiest (and therefore most useful) grunge fonts come from font houses like [T-26] and GarageFonts. I've also used Tema Cantante in a class syllabus (see figure 4) and have used Monkey Caught Stealing in class

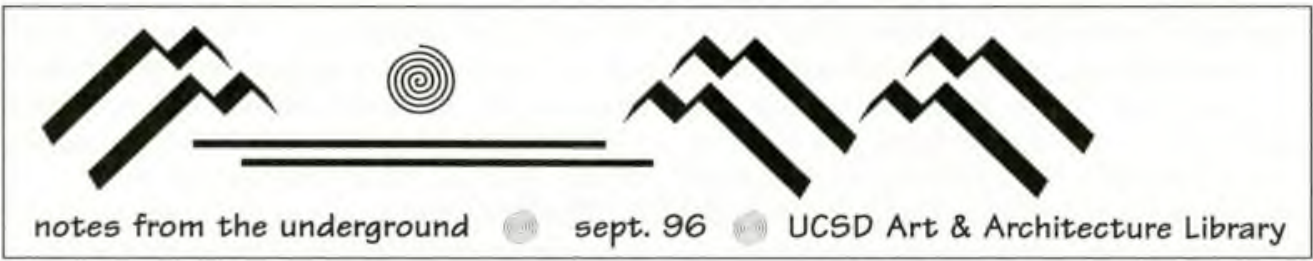

Figure 3. A sample of the font Tekton. 
Week 7 - October 17

Individuals present websites to class

and discuss.

Learn Photoshop and scanning.

Review your writing.

Continue working on second project.

Read: chapter 7 and 8 of Drucker. $\}$ Assignment

Individuals working to complete project 2.

Assignment $\{$ Continue working on second project.

Read: chapter 9 of Drucker.

Figure 4. Tema Cantante for the heads and Officina for the text.

\section{Font wars}

Font wars are like platform wars (PCs vs. Macs)—there may or may not be a right answer, but a true believer will argue with you for hours over their preference

Most fonts are either "Type 1," a standard created by Adobe for printing with Postscript printers, or

handouts. Amnesia was used as the text for a grant request, and as you can see in figure 2 , it might say to an undergraduate, "Hey, this is cool. I might want to do this." I use a shareware font, Vintage Typewriter, instead of Conrier or American Typeuriter when I want to indicate something to type on screen-it makes the document look a lot less like a technical manual.

You have to be more careful when designing with these fonts because you can easily cross the edge into illegibility. But used in the right places, they can be very effective. Though Tema Cantante comes in serif and sans-serif families, for the most part grunge fonts come in varying degrees of dirt. For example, Image Club sells a font that comes as Schmutz Cleaned, Schmutz Clogged, and Schmutz Corroded.

\section{A picture is worth a thousand layout tricks}

One last type of font, often overlooked but which can really add a lot to your work, is picture fonts (fonts that show a symbol or an image when you type a "letter"). The simple addition of a border (see figure 5) can liven up a page. Bullets clon't have to be plain circles or those drop shadow boxes that were so popular for years - the choice of "dingbat" fonts are more numerous and more varied than those of you who only have Zapf Dingbats can imagine (though Zapf Dinghats are wonderful and should be a standard part of everyone's type library).

Picture fonts are also extremely useful when you need a symbol. The first time I needed the symbol of a person in a wheelchair, I had to find a symbol dictionary, scan the image, clean it up, and then import it into PageMaker. Now I can just type " $\mathrm{H}$ " in International and the image is there in a cleaner form and in about an hour's less time. While clip-art serves a similar purpose, I find picture fonts more useful because they can be "typed" in instead of imported or "placed."
"TrueType," a competing standard created by Apple and used in Windows in a Microsoftmodified form.

You will find proponents for both. Type 1 fonts require both an "outline" and "bitmapped" version of the file and require Adobe Type Manager (ATM) to display and print clearly. They generally add more files to your computer, though the files themselves are smaller. TrueType fonts do not need ATM or outline files and only require one file for all bitmapped sizes.

It sounds like there's no contest, go with TrueType, but if you are using programs such as PageMaker or FreeHand and printing to Postscript printers, Type 1 fonts are best. If you don't use those programs, you might be better off with TrueType fonts, though not all designer fonts come in TrueType versions.

\section{$1+1$ may not $=2$}

When you start to increase your font library, it is very tempting to go with the sets that offer 1,000 fonts for the price of one Adobe or Emigre set. There is a good reason the fonts in those sets are so cheap-they are not as well designed. Designing takes two flavors: one is the shape of the letters themselves (which may not be as critical in grunge fonts but is essential in more traditional book faces); and the other is how the letters fit together. Notice the capital "T"s in this article. See how the overlap of Ty is slightly more than the overlap of $\mathrm{Tr}$ and how there is no overlap for Th-these are called kerning pairs, and how individual letters fit together is almost as important for ease of reading as the shape of the letters themselves. Many of the cheaper fonts are cheaper because the designer did not take the extra time needed to make sure the font spacing works. You get what you pay for:

The other reason these font sets might be cheaper is that there are some font vendors who are taking designer fonts and merely re- 
naming them without making any changes to the design. It's up in the air as to whether or not this is an illegal practice, but it is surely unethical and deprives the font designer of revenule.

\section{Shop till you drop, legally}

There are four ways to acquire fonts, and the first is illegal and shouldn't be considered. Do not take fonts from friends. It makes fonts more expensive for the rest of us who do. The legal ways follow

\section{Purchasing fonts}

Font prices are coming down, so there is no excuse for "borrowing." Even the "I'll only use it once excuse" is lanne. You don't know that. I bought Eurostile for a freelance project I was working on, and it has proved to be useful in many other unpredicted (at time of purchase) projects.

- High-end (more than \$75). Sometimes you want a font because you like the way it looks and buying that font package is the only way to get it. Only four of the fonts used in this article fit this category, Eurostile, Optima, Mason, and Tema Camtante, but I liked them so much, and use them so much, it was worth the purchase.

If you want to acquire a complete font family that comes in a variety of weights (light, book, bold, ultra) and may have a conclensed version and an expert collection (these usually inclucle small caps, fractions, special characters), you will also have to pay for it. But then you will have an all-purpose font that you can use for most of your textual needs.

- Mid-range (\$40-\$75). Font prices really are dropping. Fonts that used to be high-end are now micl-range, and some font houses, like FontBureau, sell different styles or weights in font families (bold. italic, serif/sans-serif, etc.) separately so you only liave to purchase the ones you want and don't have to pay for a complete set. Some of the stylish [T-26] and Emigre fonts are in this price range too. You can make a great state. ment with just a little investment. Fonts in this category include Rubino, Sundance, Encaliptus, and Serpentine.

- Low-end (below \$40). There are lots and lots and lots of low-end fonts out right now. Some of them aren't worth the bits they take on your hard drive and others are more than worth the price. One of my favorite fonts in this category is Letraset Papyrus, which costs only $\$ 29$. Also in this category: Russell Square, Intention, and Isadora. The Imatge Club cata$\log$ is one of the best sources for low-priced fonts, and the funky GarageFont fonts are in this category too. Most picture fonts are also in this price range.

- Sets. You can also buy fonts in sets. Font houses like Adobe, Emigre and Font Haus sell font packages that include a number of different fonts for prices less than buying each font separately. User groups and discount houses also sell font sets, though in my experience the shareware and cheaper-priced sets are not the same quality (see above). But if you are just getting started, it is a good way to get a variety without having to take a second mortgage on your house. The benefit of these cheaper fonts is that they often have differently named knockoffs of designer fonts for a fraction of the cost. An example is the font called not-Peignot in figure one, a copy of Adobe's Peignot. The downside is that they are not as good (notice the uneven spacing of not-Peignot's letters) and should be used only in very small doses.

- CD. Adobe and Agfa are just two of the companies that sell fonts on CD. You pay a small price for the Cl) (or receive it free with software), and then you "unlock" the fonts for a price that is cheaper than buying them indiviclually. You usually also get free fonts for just registering the disk - this is how I got Bengutiat Gothic and Grimalkin Borders. Also, there are

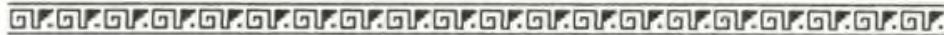

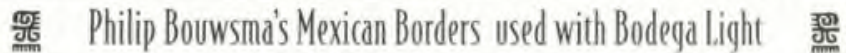

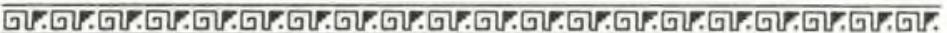

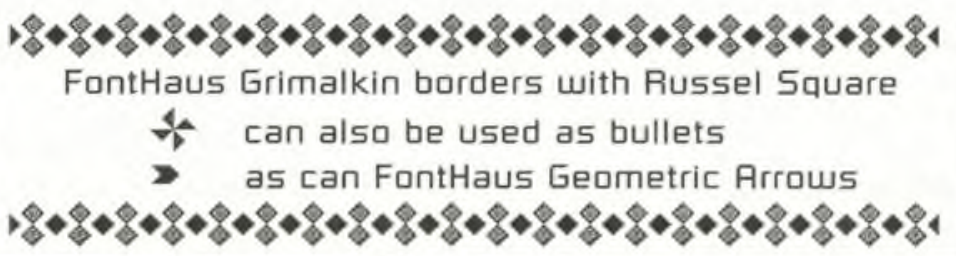

Figure 5. Borders can be fun. 
often specials, as in a recent one where Agfa was selling all fonts for $\$ 7$ each (some being as much as $\$ 40$ each regularly). This way I was able to pick up many fonts I've wanted for a long time but couldn't afford otherwise. From this category come Bodega, Burean Empire, and Bodoni Ornaments.

\section{Purchasing software}

The latest versions of Adobe Illustrator and Macromedia Freehand come with enough good fonts to justify the software purchase (especially at academic prices). Always check the "goodies" or "extras" folders on software CIDs for these hidden treasures. Fxcept for Eurostile and Optima, all the Adobe fonts illustrated in this article came with software, including Rubino and Whassis. URW Bodoni came with Macromedia's X-Res.

\section{Downloading}

There are an amazing number of free fonts on the Web, all you need to know is where to look. Also, by going to these sites, you can get an idea of what other fonts are available from the vendors, how much they cost, and if you like them enough you can order them right there. Many vendors will also send you the fonts on e-mail.

Two of my favorite sites are Letraset (www.esselin.com/letraset) and the "Directory to Type Foundries" from Publish magazine (www.publish.com/treasury/directories/ foundry/) because you can download quality fonts for free. The Directory page is also one of the best sources for information about foundries in general, with addresses, phone numbers, and Web sites when available. ImageClub (www.imageclub.com) is a good site because it has so many reasonably priced fonts to browse. Glastonbury and the wonderfully named Monkey Caught Stealing were downloaded from the Web. One warning: free fonts often do not have the range of styles and sizes you would get if you purchased the font.

There are also a large number of freeware and shareware fonts out there. The quality varies from font to font, but some of them are quite nice, like International, Vintage Typeuriter, and Louer West Side.

\section{Other sources}

While not all sites give you free fonts, they are still fun to browse and purchase from. Often, as with the Enigre (www.emigre.com), Font
Bureau (www.fontbureau.com), and Garagefonts (WWW.GarageFonts.Com) sites, they are also very good examples of well-designed Web sites.

Those companies, and many more also have printed catalogs. The Emigre catalog has lots of great examples of creative uses of fonts. The Font Bureau catalog doesn't resort to the traditional fox and lazy dog to show off its letters but has phrases like "the iguana in the tollbooth was helpful and polite." The [T-26] (www.t26font.com) catalog is packaged like an artists' book, coming in a burlap bag with postcards and other font samples as well as the traditional (for them) catalog. The TypeArt (www.typeart.com) font catalog offers a 100piece set of Font Soldiers (it's a joke) and the GarageFonts catalog is so much fun that its "swimsuit edition" is inclucled in a current exhibit at the Cooper Hewitt National Design Museum.

The standard type catalogs, like Aclobe (www.adobe.com), Agfa (www.agfa.com), ITC (http://www.esselte.com/itc), and Image Club (www.imageclub.com) are also not to be ignored because they show the wide variety of type available. And for the truly obsessed, Agfa and Emigre are two of the houses that also send you font posters and, yes, the posters are hanging up in my office.

\section{Further reading}

Two of the best books around (and in spite of their titles are applicable to all computers), are Robin Williams's The Mac Is Not a Typewriter and Beyond the Mac Is Not a Typeuriter, both from Peachpit Press and generally available in the computer section of any bookstore. The first does come in a PC Is Not a Typeuriter version. Williams's Blip in the Continuum (Mac and $\mathrm{PC}$ versions available) includes a floppy disk with more than 20 "ugly" fonts, including Filet and Hard Tack.

\section{Also recommended}

Bringhurst, Robert. The Elements of Typographic Style. Hartley \& Marks, 1992.

Any issue of Emigre magazine, Sacramento, California.

Spiekermann, Erik. Stop Stealing Sheep E Find Out How Type Works. Adobe Press, 1993.

Tschichold, Jan. The Neu' Typography: A Handbook for Modern Designers. University of California Press, 1995 (originally published in German in 1928). 


\section{BUILDING INTELLIGENT SYSTEMS FロR YaUR WDRLD DF INFロRMATIDN.}

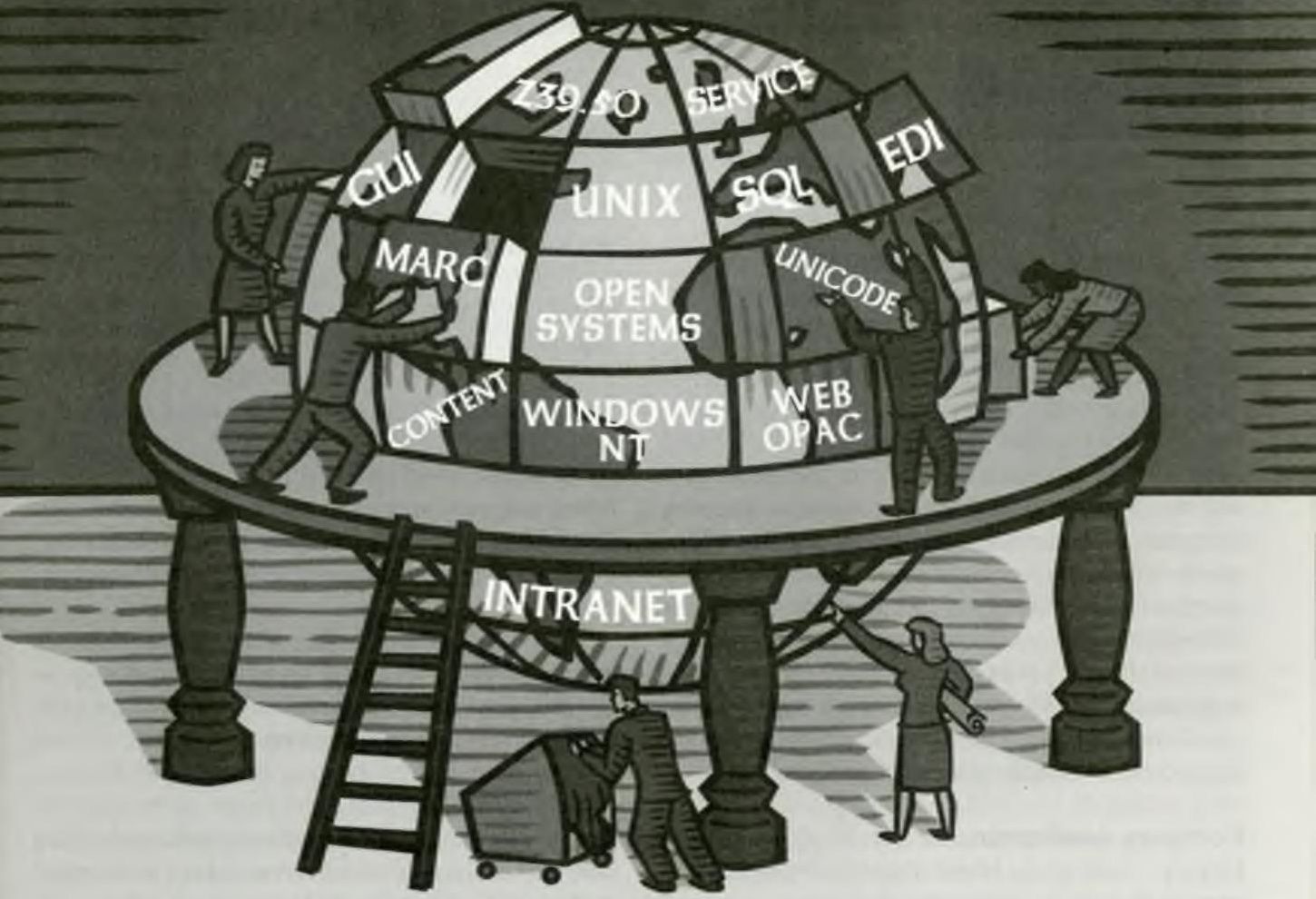

It's challenging being a librarian in the 90's - trying to fit all the technology pieces together for the future.

But EOS International is here to help. Our scaleable library software is being used in all types of libraries around the world. The standards you need for tomorrow are built into our software today. EOS systems architecture is open and portable. Searching modules use intuitive navigation, hyperlinks, and other third-generation tools to connect you and your users to the world of information.

Though our name is new, we have been working with librarians like you for over fifteen years. We are helping over 6,500 libraries worldwide put the pieces together. Why not yours?

800-876-5484 http://www.eosintl.com
- WEB/OPAC

- Cataloging

- Circulation

- Serials Control

- Acquisitions

- Service \& Training

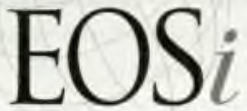

INTELUGent SYSTEMS. BY DESIGN 